\title{
Educational mismatches versus skill mismatches: effects on wages, job satisfaction, and on-the-job search
}

\author{
By Jim Allen ${ }^{\star}$ and Rolf van der Velden $\dagger$ \\ ${ }^{*}$ Research Centre for Education and the Labour Market, University of Maastricht, \\ Postbus 616, 6200 MD Maastricht, The Netherlands; \\ e-mail: J.Allen@ROA.UNIMAAS.NL. \\ $\dagger$ Research Centre for Education and the Labour Market, University of Maastricht
}

\begin{abstract}
Education-job mismatches are reported to have serious effects on wages and other labour market outcomes. Such results are often cited in support of assignment theory, but can also be explained by institutional and human capital models. To test the assignment explanation, we examine the relation between educational mismatches and skill mismatches. In line with earlier research, educational mismatches affect wages strongly. Contrary to the assumptions of assignment theory, this effect is not explained by skill mismatches. Conversely, skill mismatches are much better predictors of job satisfaction and on-the-job search than are educational mismatches.
\end{abstract}

\section{Introduction}

Education-job mismatches are reported to have serious effects on a number of labour market outcomes. Overeducation is known to affect labour turnover (Topel, 1986; Hersch, 1991), occupational choice (Viscusi, 1979), and job satisfaction (Tsang and Levin, 1985). A major line of research has been developed regarding the effect of education-job mismatches on wages. Empirical results suggest that both individual human capital and job characteristics are related to wages. Individuals working in jobs for which a lower level of education than their own is required (overeducation) are often found to earn less than individuals with the same level of education working in jobs for which their own level is required (adequate education), but more than individuals working in an equivalent job with the level of education actually required (Duncan and Hoffman, 1981; Hartog and Oosterbeek, 1988; Sicherman, 1991; Hersch, 1991; Cohn and Khan, 1995; Van Smoorenburg and Van der Velden, 2000). Conversely, individuals working in jobs for which a higher level is required (undereducation) often earn more than individuals with the same level of education working in jobs for which their own level is required, but less than individuals with the level of education actually required in such jobs. The wage effects of overeducation are usually stronger than the wage effects of undereducation. 
Such results are often cited in support of so-called 'assignment' models of the labour market (Sattinger, 1993), whereby the returns to additional investments in human capital depend in part on the match between the worker and the job. The basic idea is that, although higher education raises productivity in general, the actual level of productivity realised is also determined by the match between educational level and job level. Working in a job below one's own level imposes a limitation to the utilisation of skills. The lower level of the job in effect imposes a ceiling on the worker's productivity, resulting in lower wages. Conversely, working in a job above one's own level in effect raises this 'productivity ceiling', allowing workers to be more productive than they would be when working at their own level. However, in this case, the worker's own abilities are the main factor limiting productivity. Because workers employed in a job at their own level are already performing at a level close to their own personal productivity ceiling, the wage benefits of working above one's own level are generally modest. This accounts for the observed asymmetry in the wage effects of over- and undereducation.

According to assignment theory, the allocation is optimal when workers are allocated top-down according to their skills, whereby the most competent worker is assigned to the most complex job and the least competent worker is assigned to the simplest job. ${ }^{1}$ The incidence of educational mismatches can thus be explained by differences in the shares of complex jobs and skilled workers. However, as Hartog (2000) has pointed out, over- and undereducation can also be explained in other ways. According to search and matching theory, temporary mismatches may occur as a result of imperfect information. The fact that overeducation is typically higher in the phase of the transition from school to work is often taken as evidence for this interpretation. However, others have argued, from the point of view of human capital theory, that the high incidence of overeducation among school-leavers reflects these workers' lack of work experience (Groot and Maassen van den Brink, 1996).

This human capital argument can be stated in a more general way, to provide an alternative explanation for the effects normally attributed to assignment theory. Although the intuitive appeal of assignment theory is considerable, the wage equations used are not directly derived from assignment theory (Hartog, 2000). The observed wage differences for jobs below and above one's own level might just as easily reflect individual differences in human capital within education levels, which are roughly sorted according to job level. Those working 'below their own level' are in that case less productive on average than those working 'at their own level', not because the job imposes limitations on their productivity, but because they have less human capital on average to begin with. Similarly, those working

\footnotetext{
${ }^{1}$ In addition to the effects of a mismatch between required and actual level of education, many studies also take into account the effects of working in a job for which a field of education different from one's own field is required.
} 
'above their own level' have according to this view more human capital on average than those working at their own level.

Institutional theories offer yet another possible explanation for the same observed wage effects. They point out that employers often forced to base wages on easily observable characteristics of employees or jobs, rather than on individual performance (Thurow, 1975). From such a perspective, the observed wage differences could be accounted for by the fact that both the formal education of employees and the required education for the job are frequently incorporated in wage scales as determined in collective bargaining agreements. The differences may not reflect individual differences in productivity, but rather the value assigned to education and job categories in such agreements.

Wage analyses based on attained and required education cannot in themselves provide a definitive answer to the question of which explanation is correct. The aim of this article is to shed some further light on this discussion, by examining the relation between the education-job match on one hand and the utilisation of individual skills on the other. The basic idea is that the above-mentioned theories differ in the way they postulate a relation between the 'formal' education-job mismatch (hereafter called educational mismatches) and the actual mismatch between acquired and required skills (hereafter called skill mismatches).

In assignment theory, educational mismatches imply skill mismatches. Skill mismatches are believed to account for the observed wage effects of over- and undereducation. If the assignment explanation is valid, we should therefore find that individuals working below their own level are underutilising their knowledge and skills to a significant degree, while individuals working above their own level lack some of the knowledge and skills that are required in order to perform optimally in their job. We would also expect the effects of education-job match in wage analyses to be accounted for to a large extent by mismatches in the utilisation of knowledge and skills. The same applies to effects on other outcomes like job satisfaction and intention to quit.

This paper puts the assignment theory to the test. If educational mismatches do not imply skill mismatches, and skill mismatches do not account for the effects of educational mismatches on wages and other outcomes, assignment theory is seriously challenged. In the paper we address the following questions:

(i) to what extent do skill mismatches correspond to mismatches between available and required education in jobs?

(ii) to what extent can wage effects of educational mismatches be accounted for by skill mismatches?

(iii) to what extent and in what ways do skill mismatches and educational mismatches influence job satisfaction?

(iv) to what extent and in what ways do skill mismatches and educational mismatches influence employees' decisions to actively seek other employment? 


\section{Data}

The data used for the analyses were collected for the project 'Higher Education and Graduate Employment in Europe', an international comparative study of the labour market situation of graduates from tertiary education in 11 European countries and Japan. ${ }^{2}$ In the Netherlands two main types of graduates from tertiary education are distinguished: those who graduate from university, and those who graduate from a college for higher vocational education. Two graduate cohorts were approached at the end of 1998. The first cohort consisted of a representative sample of those graduating from tertiary education in the academic year 19901991. The second cohort comprised a representative sample of those who graduated in the academic year 1994-95. For this article the Dutch data from the former cohort are used, which means that our subjects are individuals who graduated from tertiary education some seven years prior to the survey. Around 6000 graduates were approached, of which 2723 responded with a completed questionnaire. The analyses are restricted to the 2460 individuals who at the time of the survey were in paid employment for at least 12 hours per week. From these 2460 individuals 901 graduated from university and 1559 from higher vocational education in the academic year 1991. (For further information we refer to Allen and Van der Velden (forthcoming).

\section{Educational mismatch and skill mismatch}

Various measures have in the past been proposed to indicate the match between education and job. In this article we use an employee self-rating of the level of education most appropriate for the current job, with response categories: university plus postgraduate study (1); university only (2); higher vocational education plus postgraduate study (3); higher vocational education only (4); secondary vocational education or equivalent (5); or lower (6). By comparing this to the highest attained level of education of the workers, ${ }^{3}$ we can determine whether, and to what extent, respondents are working above or below their own level. For the Netherlands, Van der Velden and Van Smoorenburg (1997) have shown that workers' self-ratings are far more valid than a commonly used alternative, namely the expert-rating of job titles. From the point of view of matching theory, 'appropriate level' is preferable to the often-used alternative of 'required level'. The latter measure may partly measure formal selection requirements, whereas the former is more likely to refer to actual job content.

\footnotetext{
${ }^{2}$ This project was partially funded by the European Commission under the Targeted Socio-Economic Research (TSER) program (TSER EGS-SOE2-CT97-2023), with additional funding by the Dutch Ministry of Education. The project is coordinated by Prof. U. Teichler from the University of Kassel.

${ }^{3}$ Many of those who graduated from a university or higher vocational education institute in 1990/1991 subsequently earned a higher degree within tertiary education.
} 
Next we asked the respondents to indicate which field of education is most appropriate for their job, with response categories: 'only my own field of education' (1); 'my own or a related field' (2); 'a completely different field of education' (3); 'for this job no specific field is required' (4); and 'for this job no specific field (yet) exists' (5). We collapsed these five categories into two by distinguishing categories (1) and (2) from (3), (4), and (5).

Examination of the data reveals that educational mismatches are a common phenomenon. A considerable percentage of higher vocational education graduates (14\%) and university graduates (8\%) were working in jobs for which they considered a (somewhat) higher level of education was more appropriate. ${ }^{4}$ About a third of the higher vocational education and university graduates indicated that they were working in a job for which they considered a lower level of education would have been more appropriate. Finally, around one in five graduates were working in jobs for which their own or a related field of education was not considered most appropriate. In all, some $50 \%$ of university graduates and $56 \%$ of higher vocational education graduates worked in jobs for which they considered a level and/or field of education other than their own to be more appropriate.

At first sight, it seems rather alarming that such a large proportion of the most highly trained category of participants in the Dutch labour market have jobs which don't match their education. How serious is this? Specifically: to what extent do such mismatches between own and required education correspond to mismatches between the knowledge and skills possessed by subjects and the knowledge and skills required in their work? To investigate this, subjects were asked to indicate the extent to which they agreed with the following statements:

Statement 1 My current job offers me sufficient scope to use my knowledge and skills.

Statement 2 I would perform better in my current job if I possessed additional knowledge and skills.

The responses (on a five point scale) to statement 1 indicate the degree to which available skills are being utilised in the current job, and the responses to statement 2 the extent to which the respondent possesses the skills required in the job. Underutilisation, the skills counterpart of overeducation, is thus indicated by the extent to which one disagrees with statement 1. A Skill deficit, the skills counterpart of undereducation, is indicated by the extent to which one agrees with statement 2 . The relation between these measures of skill mismatches and educational mismatches are shown in Table 1.

\footnotetext{
${ }^{4}$ These figures include those who have completed some form of postgraduate study within higher vocational education and university respectively.
} 
Table 1 The relation between educational mismatches and skill underutilisation

\begin{tabular}{lrrrrrr}
\hline & \multicolumn{3}{c}{ None } & & \multicolumn{2}{r}{ Strong } \\
Skills underutilisation & 1 & 2 & 3 & 4 & 5 \\
\hline Education-job match & & & & & \\
University & 42 & 42 & 13 & 1 & 1 \\
Higher level of education appropriate & 34 & 48 & 11 & 6 & 2 \\
Own level and field of education appropriate & 30 & 48 & 14 & 6 & 2 \\
Own level and different field of education appropriate & 14 & 37 & 20 & 21 & 8 \\
Lower level of education appropriate & 28 & 44 & 15 & 10 & 4 \\
Total university & & & & & \\
Higher vocational education & 25 & 51 & 16 & 6 & 2 \\
Higher level of education appropriate & 30 & 42 & 15 & 10 & 3 \\
Own level and field of education appropriate & 18 & 49 & 20 & 6 & 8 \\
Own level and different field of education appropriate & 20 & 38 & 21 & 15 & 6 \\
Lower level of education appropriate & 25 & 42 & 18 & 11 & 5 \\
Total higher vocational education & 26 & 43 & 16 & 11 & 4 \\
Total university + HVE & & & & & \\
\hline
\end{tabular}

About $15 \%$ of all graduates experience a high or very high degree of underutilisation of skills as indicated by their response to statement 1 . The pattern of answers is clearly related to educational mismatches. The relation is, however, far from perfect. As might be expected, a large majority of tertiary graduates working in jobs for which their own or a higher level and their own or a related field of education was considered appropriate appear to be quite satisfied with the scope which their job provides for using their knowledge and skills. Somewhat surprisingly however, a relatively large proportion of graduates working in jobs below their own level and/or outside their own field also report little or no underutilisation. This is particularly the case for university graduates. Furthermore, even graduates whose education matches their jobs sometimes report rather severe underutilisation. All in all, these results suggest that while a good match in terms of formal education improves the chances that one will be given the opportunity to use one's knowledge and skills, it is neither a necessary nor a sufficient condition for skill utilisation.

In effect, statement 1 takes the skills of the subject as given, and seeks to determine the extent to which the subject is in a position to utilise these in the current work setting. Statement 2 switches the perspective around, taking job requirements as given, and seeking to establish to what extent the subject is equipped to fulfil these requirements. Table 2 provides an overview of skill deficits as measured by the responses to statement 2 .

Somewhat unexpectedly, a large proportion of all categories of graduates show rather high levels of skill deficits according to this measure. This could indicate that statement 2 has a low threshold value, in the sense that subjects agree with the 
Table 2 The relation between educational mismatches and skill deficits

\begin{tabular}{|c|c|c|c|c|c|}
\hline \multirow[b]{2}{*}{ Skills deficits } & \multicolumn{3}{|c|}{ None } & \multicolumn{2}{|c|}{ Strong } \\
\hline & 1 & 2 & 3 & 4 & 5 \\
\hline \multicolumn{6}{|l|}{ Education-job match } \\
\hline \multicolumn{6}{|l|}{ University } \\
\hline Higher level of education appropriate & 13 & 19 & 21 & 26 & 21 \\
\hline Own level and field of education appropriate & 7 & 19 & 23 & 37 & 15 \\
\hline Own level and different field of education appropriate & 9 & 6 & 22 & 43 & 20 \\
\hline Lower level of education appropriate & 7 & 18 & 22 & 38 & 15 \\
\hline Total university & 8 & 18 & 22 & 37 & 16 \\
\hline \multicolumn{6}{|l|}{ Higher vocational education } \\
\hline Higher level of education appropriate & 5 & 19 & 28 & 34 & 15 \\
\hline Own level and field of education appropriate & 5 & 18 & 32 & 32 & 13 \\
\hline Own level and different field of education appropriate & 10 & 14 & 18 & 33 & 26 \\
\hline Lower level of education appropriate & 10 & 20 & 28 & 30 & 13 \\
\hline Total higher vocational education & 7 & 19 & 29 & 32 & 14 \\
\hline Total university + HVE & 7 & 18 & 26 & 34 & 15 \\
\hline
\end{tabular}

statement even in the case of relatively minor skill deficits. ${ }^{5}$ This measure of skill deficit is only weakly related to education-job mismatches. Those working outside their own field appear to be somewhat more inclined to report skill deficits than those working within their own field. However, there seems to be little or no relation between job level and skill deficits. One might expect graduates who work above their own educational level to show higher levels of skill deficits than graduates working at or (especially) below their own level. This is not the case.

Taken together, the results shown in Tables 1 and 2 appear to be in conflict with one of the key assumptions of assignment theory, namely that mismatches between education and job are accompanied by serious mismatches between available skills and required skills. The results indicate only a relatively weak relation between educational mismatches and skill mismatches. ${ }^{6}$

From the point of view of the match between skills and skill requirements, skill utilisation and skill deficits as indicated by the responses to statement 1 and statement 2 are not simply two sides of the same coin. It is possible, even likely,

\footnotetext{
${ }^{5} \mathrm{~A}$ comparison with the graduates' responses based on a list of 34 separate skills indicates that the threshold is indeed somewhat low. Even those who indicated very few or no discrepancies between available and required skill items often responded positively to statement 2 . Nonetheless, there was a clear positive relation between the number of item discrepancies and the response to statement 2, suggesting that the statement has at least a certain degree of validity.

${ }^{6}$ We also used other indicators of skill utilisation and skill deficit by asking respondents to indicate for a list of skills whether they were required in the job and whether they possessed these skills. These analyses show roughly similar results, although the effects on labour market outcomes are less strong.
} 
Table 3 Combinations of skill underutilisation and skill deficits

\begin{tabular}{lccc}
\hline & $\begin{array}{c}\text { Skill deficits } \\
\text { none/weak }\end{array}$ & strong & total \\
\hline Skill underutilisation & & & \\
None/weak & skill match & skill shortage & $84.8 \%$ \\
& $41.8 \%$ & $43.0 \%$ & \\
Strong & skill surplus & wrong skills & $15.2 \%$ \\
& $9.3 \%$ & $6.0 \%$ & \\
Total & $51.0 \%$ & $49.0 \%$ & $100.0 \%$ \\
\hline
\end{tabular}

that some people will simultaneously experience shortages and surpluses of (different) skills. To illustrate this, Table 3 shows different combinations of the two measures.

Table 3 reveals that the responses to the two statements are only quite weakly related: those who disagree with statement 1 are slightly less likely to agree with statement 2 than those who do not disagree with statement 1 and vice versa. A small group $(6 \%)$ of graduates simultaneously report that their job does not offer them sufficient scope for using their knowledge and skills and that they could do their work better if they possessed additional knowledge and skills. This group of graduates does not so much suffer from having too little or too few skills for their jobs, as from having the wrong skills.

\section{The model}

In each of the analyses on the effects of educational mismatches and skill mismatches on wages, job satisfaction and on-the-job search, we will use similar models. We will begin with a model containing indicators of acquired level of education, with as control variables labour market experience before the start of current job, ${ }^{7}$ tenure in current job, and dummies for self-employment and temporary employment. The model specification is:

$$
Y=a_{0}+a_{1} X+a_{2} \mathrm{EDUC}+e
$$

With $Y=$ dependent variable under consideration (i.e. log wages, job satisfaction, looking for another job); $X=$ a vector of control variables, and $E D U C=a$ set of dummies indicating the acquired educational level.

The dummies representing the educational level are as follows: university plus postgraduate study (UE+), university education only (UE), higher vocational education plus postgraduate study ( $\mathrm{HVE}+$ ), and higher vocational education only (HVE) as the reference category.

\footnotetext{
${ }^{7}$ We used age at the start of the current job as a proxy for prior labour market experience.
} 
In model (2) we add the mismatches according to the formal educational requirements for the job

$$
\begin{aligned}
Y= & \text { model } 1+a_{3} \text { UNDEREDUC }+a_{4} \text { OVEREDUC } \\
& +a_{5} \text { OWNFIELD }+e
\end{aligned}
$$

With UNDEREDUC $=$ degree to which job level is higher than own schooling level, OVEREDUC $=$ degree to which job level is lower than own schooling level, and OWNFIELD = dummy indicating if one's own or a related field of education is considered appropriate (1), zero otherwise.

The variables OVEREDUC and UNDEREDUC are measured in terms of the number of years normally required for the subject's own level of education and for the level of education considered most appropriate for the current job. Each level of education is assigned a score depending both on the nominal length and the difficulty of the educational track. The following scores are used: UE+ (21), UE (19), HVE+ (18), HVE (17), secondary education and lower (14) (cf. Van der Velden and Van Smoorenburg, 1997). In line with previous research we distinguish between the effects of overeducation and undereducation. Years of overeducation have been calculated by subtracting the actual level of education from the appropriate level of education, with all negative scores set to zero. For years of undereducation the reverse has been applied, again setting all negative scores to zero. The reference category for both variables is having a matching job. Because the model specification includes the respondent's actual level of education instead of required level, the assignment theory predicts in model 2 a negative effect of overeducation, since in this specification overeducation implies a job at a lower level. Similarly the theory predicts a (somewhat smaller) positive effect of undereducation.

In order to ascertain to what extent any effects of educational mismatch are due to skill underutilisation and/or deficits, models 3 and 4 incorporate measures for the two types of skill mismatch. In model 3 we replace the terms representing overand undereducation by the respondents' judgements of skill utilisation and deficits, as measured by the responses to statements 1 and 2. The scores on statement 1 are recoded such that a high score indicates high underutilisation.

$$
Y=\text { model } 1+a_{6} \text { UNDERUTILISATION }+a_{7} \text { DEFICIT }+e
$$

with UNDERUTILISATION $=$ measure based on recoded response to statement 1 and DEFICIT $=$ measure based on response to statement 2 .

Models 2 and 3 contain specifications of the effects of the two types of mismatches on labour market outcomes. For model 3, assignment theory leads to the prediction of a negative effect of underutilisation, analogous to the negative effect predicted for overeducation. The theory also predicts a (somewhat counterintuitive) positive effect of skill deficits, which are interpreted here as the skill counterpart of undereducation. A skill deficit thus indicates a job above one's own level. A comparison of these models will provide an indication of which kind of mismatch has the stronger overall effect on the outcome in question. 
More interesting from our point of view is a model specification in which both educational mismatches and skill mismatches are included together. This will allow us to determine the net effect of each kinds of mismatches after controlling for the effect of the other. This specification is shown in model 4

$$
Y=\text { model } 2+a_{6} \text { UNDERUTILISATION }+a_{7} \text { DEFICIT }+e
$$

\section{The effects of mismatches on wages}

Table 4 presents the results of the analysis on the (natural $\log$ ) of hourly wages. Model 1 shows that only $12 \%$ of the wage differences can be explained by the variables in the model. This seems quite low, but but one should bear in mind the relative homogeneity of the group in terms of basic human capital aspects. There are in fact quite large differences between the different educational levels acquired. Having followed university education rather than higher vocational education yields a wage increase of $23 \%(\exp (0.211))$. Having followed university plus

Table 4 Results of regression-analyses with dependent variable ln (hourly wage)

\begin{tabular}{|c|c|c|c|c|c|c|c|c|}
\hline \multirow{2}{*}{$\begin{array}{l}\text { Dependent variable: } \\
\ln (\text { hourly wage })\end{array}$} & \multicolumn{2}{|c|}{ Model 1} & \multicolumn{2}{|c|}{ Model 2} & \multicolumn{2}{|c|}{ Model 3} & \multicolumn{2}{|c|}{ Model 4} \\
\hline & B & $\mathrm{SE}$ & B & SE & B & SE & B & SE \\
\hline \multicolumn{9}{|c|}{$\begin{array}{l}\text { Human capital } \\
\text { Level of education (reference group HVE) }\end{array}$} \\
\hline $\begin{array}{l}\text { University }+ \\
\text { postgraduate study }\end{array}$ & $0.262^{\star}$ & 0.023 & $0.316^{*}$ & 0.023 & $0.244^{*}$ & 0.023 & $0.304^{\star}$ & 0.023 \\
\hline University & $0.211^{\star}$ & 0.018 & $0.247^{\star}$ & 0.018 & $0.206^{*}$ & 0.018 & $0.243^{\star}$ & 0.018 \\
\hline $\begin{array}{l}\mathrm{HVE}+ \\
\text { postgraduate study }\end{array}$ & $0.073^{*}$ & 0.018 & $0.110^{*}$ & 0.017 & $0.065^{\star}$ & 0.018 & $0.103^{\star}$ & 0.018 \\
\hline Tenure in current job & $0.011^{\star}$ & 0.002 & $0.010^{*}$ & 0.002 & $0.011^{\star}$ & 0.002 & $0.010^{\star}$ & 0.002 \\
\hline $\begin{array}{l}\text { Experience before } \\
\text { current job }\end{array}$ & $0.011^{*}$ & 0.001 & $0.011^{\star}$ & 0.001 & $0.011^{\star}$ & 0.001 & $0.011^{\star}$ & 0.001 \\
\hline Job characteristics & & & & & & & & \\
\hline temporary job & $-0.145^{\star}$ & 0.022 & $-0.154^{\star}$ & 0.021 & $-0.137^{\star}$ & 0.021 & $-0.148^{\star}$ & 0.021 \\
\hline self-employed & -0.033 & 0.024 & -0.043 & 0.023 & -0.046 & 0.024 & -0.050 & 0.023 \\
\hline Education-job match & & & & & & & & \\
\hline overeducation (years) & & & $-0.081^{\star}$ & 0.005 & & & $-0.071^{*}$ & 0.006 \\
\hline undereducation (years) & & & $0.036^{\star}$ & 0.012 & & & $0.035^{\star}$ & 0.012 \\
\hline job outside own field & & & -0.036 & 0.015 & & & 0.031 & 0.015 \\
\hline $\begin{array}{l}\text { Skill-job match } \\
\text { skill underutilisation } \\
\text { (statement } 1 \text { ) }\end{array}$ & & & & & $-0.060^{\star}$ & 0.005 & $-0.032^{\star}$ & 0.006 \\
\hline $\begin{array}{l}\text { skill deficit } \\
\text { (statement } 2 \text { ) }\end{array}$ & & & & & 0.000 & 0.005 & -0.004 & 0.005 \\
\hline Constant & $2.938^{\star}$ & 0.043 & $2.947^{\star}$ & 0.042 & $3.080^{*}$ & 0.047 & 3.033 & 0.047 \\
\hline Adjusted R2 & 0.12 & & 0.23 & & 0.17 & & 0.24 & \\
\hline $\mathrm{N}$ & 2217 & & 2188 & & 2170 & & 2141 & \\
\hline
\end{tabular}

${ }^{*}$ significant at $1 \%$ level 
postgraduate study even leads to a wage increase of $30 \% .{ }^{8}$ Postgraduate study after higher vocational education increases wages by about $8 \%$. Model 1 shows positive effects of both experience variables tenure and experience before current job, and a negative effect for having a temporary job. Being self-employed has no significant effect on wages.

In model 2 the indicators of educational mismatches are added to the model. This improves the model fit markedly, resulting in an adjusted R2 of 0.23 . There is a significant positive effect of undereducation, which confirms the prediction that holding a job for which the appropriate educational level is higher than the one followed by the respondent results in higher wages. The predicted negative effect of overeducation is also observed. In line with the predictions of assignment theory and the results obtained in earlier research, the effects of overeducation are considerably greater than those for undereducation. Each year of undereducation (working above one's level) yields a wage increase of some 4\%. Each year of overeducation (working below one's level) leads to a decrease in wages of $8 \%$. There is no significant effect of working in a job for which one's own or a related field of education is not required. It is interesting to note that taking educational mismatches into account increases the coefficients for own education. This reflects the fact that the reference group, graduates of higher vocational education without any additional postgraduate study, showed the lowest proportion of individuals working below their own level.

In model 3 we use skill mismatches instead of educational mismatches to explain wage differences. Underutilisation, the 'skills counterpart' of overeducation, shows the expected negative effect on wages. By contrast, a skill deficit appears to have no effect at all on wages. Skill mismatches account for a good deal less wage variance than do educational mismatches: the adjusted R2 amounts to 0.17 , compared to 0.23 for model 2 .

Model 4 combines both educational mismatches and skill mismatches. Both kinds of mismatches have a significant effect on wages, even when controlling for the other. However, about half of the effect of skill underutilisation disappears when educational mismatches are taken into account. By contrast, only a small part of the effects of over- and undereducation are accounted for by skill mismatches. In terms of additional explained variance, educational mismatches seem to be much more important than skill mismatches. Whereas the adjusted R2 in model 4 is just barely higher than that in model 2, it is clearly much higher than in model 3.

The results presented in Table 4 are inconsistent with the explanation given by assignment theory to the wage effects of over- and undereducation. This explanation holds that such effects reflect differing levels of productivity as the match between required and available skills is varied. In line with this expectation, we

\footnotetext{
${ }^{8}$ These wage differentials are greater than those normally found for graduates one year after graduation, indicating that the age-earnings profile for university graduates is steeper than for graduates from higher vocational education.
} 
do observe a significant negative wage effect of skill underutilisation. However, contrary to what would be expected on the basis of assignment theory, skill mismatches account for only a small proportion of the wage effects of educational mismatches. Skill deficit appears to have no effect at all. This might be due to the lower effects of undereducation in general in combination with the low threshold value of our measure of deficits.

As indicated at the start of this paper, educational mismatches have been found to affect a broad range of labour market outcomes, not just wages. Outcomes such as job satisfaction and on-the-job search are important not only to individual workers, but also from the point of view of the workings of the labour market. In particular, we would like to know to what extent and in what way dissatisfaction with the match between schooling and/or skills and the characteristics of the job constitutes a motivation for individuals to seek employment better suited to their own capabilities. In the following two sections we analyse the effects of educational and skills mismatches on the dependent variables job satisfaction and job quit intention.

\section{Mismatches and job satisfaction}

In this section we discuss the effects of mismatches and other variables on job satisfaction. Respondents were asked to rate their over-all job satisfaction on a scale from 1 (very unsatisfied) to 5 (very satisfied). This variable has been recoded into a dummy with value 1 if the respondent marked answer category 4 (satisfied) or 5 (very satisfied), and value 0 otherwise. To facilitate a comparison of effects, the same independent variables have again been included as used for the wage estimates. A number of indicators of job quality, including $\ln$ (hourly wage) itself, have also been included as control variables. The other indicators comprise the graduates' ratings of a number of aspects of their current job, namely the degree of autonomy, the variety of work tasks, the prestige associated with the job, and the opportunity to introduce their own ideas. These control variables are important, since the quality of the job might conceivably influence both job satisfaction and the responses to statements 1 and 2. Table 5 presents the results of the logistic regression analysis.

Model 1 shows that job satisfaction is strongly influenced by job characteristics. As one might expect, wages have quite a strong effect on job satisfaction, and self-employed respondents are also more satisfied. The respondents' job quality ratings, particularly for variety and room for own ideas, also show a strong effect. Surprisingly, we find no significant effect of holding a temporary job.

Model 2 shows no improvement in model fit. Overeducation-working in a job that requires a lower level of education than one's own-has a negative effect on the job occupant's satisfaction, but the effect is not significant. Undereducation has no significant effect on job satisfaction. The same applies to working in a job that does not match the respondent's field of education. 
Table 5 Results of logistic regression-analyses with dependent variable job satisfaction

\begin{tabular}{|c|c|c|c|c|c|c|c|c|}
\hline \multirow{2}{*}{$\begin{array}{l}\text { Dependent variable: } \\
\text { (very) satisfied } \\
\text { with current job }\end{array}$} & \multicolumn{2}{|c|}{ Model 1} & \multicolumn{2}{|c|}{ Model 2} & \multicolumn{2}{|c|}{ Model 3} & \multicolumn{2}{|c|}{ Model 4} \\
\hline & B & SE & B & SE & B & SE & B & SE \\
\hline \multicolumn{9}{|c|}{$\begin{array}{l}\text { Human capital } \\
\text { Level of education (reference group HVE) }\end{array}$} \\
\hline $\begin{array}{l}\text { University }+ \\
\text { postgraduate study }\end{array}$ & 0.225 & 0.224 & 0.323 & 0.237 & 0.292 & 0.238 & 0.218 & 0.253 \\
\hline University & -0.051 & 0.170 & 0.057 & 0.178 & 0.060 & 0.181 & 0.038 & 0.190 \\
\hline $\begin{array}{l}\text { HVE }+ \\
\text { postgraduate study }\end{array}$ & 0.199 & 0.162 & 0.273 & 0.170 & 0.217 & 0.172 & 0.202 & 0.181 \\
\hline Tenure in current job & -0.032 & 0.016 & -0.035 & 0.016 & -0.038 & 0.017 & -0.040 & 0.017 \\
\hline $\begin{array}{l}\text { Experience before } \\
\text { current job } \\
\text { Job characteristics }\end{array}$ & -0.007 & 0.013 & -0.008 & 0.011 & -0.002 & 0.012 & -0.003 & 0.012 \\
\hline In (hourly wage) & $0.830^{*}$ & 0.208 & $0.638^{*}$ & 0.220 & 0.458 & 0.224 & 0.499 & 0.236 \\
\hline temporary job & 0.049 & 0.195 & 0.037 & 0.200 & -0.076 & 0.208 & -0.037 & 0.213 \\
\hline self-employment & $0.797^{\star}$ & 0.300 & 0.774 & 0.303 & 0.794 & 0.315 & 0.787 & 0.318 \\
\hline autonomy & $0.204^{\star}$ & 0.062 & $0.187^{\star}$ & 0.063 & $0.197^{\star}$ & 0.066 & $0.190^{*}$ & 0.067 \\
\hline variety & $0.570^{*}$ & 0.062 & $0.572^{\star}$ & 0.063 & $0.424^{*}$ & 0.068 & $0.424^{*}$ & 0.068 \\
\hline prestige & $0.196^{\star}$ & 0.062 & $0.181^{\star}$ & 0.063 & 0.104 & 0.068 & 0.112 & 0.069 \\
\hline room for own ideas & $0.500^{*}$ & 0.066 & $0.486^{*}$ & 0.067 & $0.339^{*}$ & 0.071 & $0.353^{*}$ & 0.072 \\
\hline \multicolumn{9}{|l|}{ Education-job match } \\
\hline overeducation (years) & & & -0.134 & 0.055 & & & 0.020 & 0.061 \\
\hline undereducation (years) & & & 0.124 & 0.129 & & & 0.029 & 0.136 \\
\hline job outside own field & & & -0.190 & 0.143 & & & 0.098 & 0.152 \\
\hline Skill-job match & & & & & & & & \\
\hline $\begin{array}{l}\text { skill underutilisation } \\
\text { (statement } 1)\end{array}$ & & & & & $-0.760^{\star}$ & 0.059 & $-0.755^{\star}$ & 0.062 \\
\hline $\begin{array}{l}\text { skill deficit } \\
\text { (statement 2) }\end{array}$ & & & & & -0.129 & 0.053 & $-0.141^{\star}$ & 0.053 \\
\hline Constant & $\begin{array}{c}- \\
-7.062^{\star}\end{array}$ & 0.756 & $\begin{array}{c}- \\
-6.381^{\star}\end{array}$ & 0.814 & $\begin{array}{c}- \\
-2.230\end{array}$ & 0.884 & $-2.429^{\star}$ & 0.928 \\
\hline Model chi-square & $405.5^{\star}$ & & $416.8^{\star}$ & & $577.5^{\star}$ & & $571.7^{\star}$ & \\
\hline d.f. & 12 & & 15 & & 14 & & 17 & \\
\hline $\begin{array}{l}\text { change in chi-square } \\
\text { relative to model } 1\end{array}$ & - & & 11.3 & & 172.0 & & 166.2 & \\
\hline $\begin{array}{l}\text { change in d.f. } \\
\text { relative to model } 1\end{array}$ & - & & 3 & & 2 & & 5 & \\
\hline
\end{tabular}

${ }^{*}$ significant at $1 \%$ level.

In model 3, skill mismatches are introduced in the place of educational mismatches. In contrast to educational mismatches, skill mismatches appear to exert a strong influence on job satisfaction. The model fit is greatly improved. Skill underutilisation has a strong negative effect on satisfaction. The effect of skill deficits is also negative, although not significant. Skill mismatches account for a considerable part of the effects of job quality indicators. Notably, the effects of wages and prestige are no longer significant. 
Model 4 incorporates both educational and skill mismatches. This model fits the data less well than model 3, despite the additional three degrees of freedom used. Interestingly, in model 4 the effect of skill deficits is now (just) significant. These results show that skill mismatches really matter to workers. Even after controlling for a range of job quality indicators, a poor match between available and required skills has a strong negative effect on job satisfaction. In the following section, we attempt to determine to what extent this effect constitutes a motivation on the part of workers to seek alternative employment.

\section{Mismatches and on-the-job search}

We have seen that, although skill mismatches only have rather moderate effects on wages, they have a strong impact on job satisfaction. An important question now is whether this has any real behavioural consequences for employees. Are workers who experience a poor match between their own skills and those required in their current job motivated by this to quit their job in favour of other work? In this section we examine effects of mismatches on the likelihood that respondents are looking for alternative employment. We asked the respondents whether they had actively sought other work in the past four weeks. Table 6 presents the results of the logistic regression analysis.

Model 1 shows that on-the-job search is strongly influenced by the variety of work tasks and the room to introduce own ideas. Other characteristics that showed an effect on satisfaction, such as wages, don't appear to constitute a sufficient motivation to actively seek other work.

Model 2, in which educational mismatches have been introduced, does not fit the data significantly better than model 1 . A poor match between formal schooling and that considered appropriate to the job does not increase the probability that a worker will seek other employment.

Model 3 shows that skill mismatches, in particular underutilisation of skills, do have real consequences, in terms of on-the-job search behaviour. The model fit is improved considerably by the introduction of these two variables. Workers who report an underutilisation of skills are significantly more likely to look for alternative employment than those who report little or no underutilisation. Skill deficits also have a positive effect, although this is not significant. Interestingly, on controlling for the effects of skill mismatches, wages now also show a significant positive effect on on-the-job search. By contrast, the effects of variety and opportunity to introduce own ideas are no longer significant.

As was the case in the analyses of job satisfaction, model 4 resembles model 3 greatly. Taking educational mismatches into account increases the effect of skill deficits to the point of significance, but negates the significant effect of wages. The results establish that skill mismatches clearly have behavioural consequences. In fact, of all the variables, only skill mismatches show a significant effect on on-thejob search. 
Table 6 Results of logistic regression-analyses with dependent variable looking for other work

\begin{tabular}{|c|c|c|c|c|c|c|c|c|}
\hline \multirow{2}{*}{$\begin{array}{l}\text { Dependent variable: } \\
\text { looking for } \\
\text { other work }\end{array}$} & \multicolumn{2}{|c|}{ Model 1} & \multicolumn{2}{|c|}{ Model 2} & \multicolumn{2}{|c|}{ Model 3} & \multicolumn{2}{|c|}{ Model 4} \\
\hline & B & SE & B & SE & B & SE & B & SE \\
\hline \multicolumn{9}{|l|}{ Human capital } \\
\hline $\begin{array}{l}\text { University }+ \\
\text { postgraduate study }\end{array}$ & 0.078 & 0.235 & 0.067 & 0.249 & 0.091 & 0.240 & 0.160 & 0.256 \\
\hline University & 0.167 & 0.187 & 0.155 & 0.195 & 0.101 & 0.192 & 0.148 & 0.201 \\
\hline $\begin{array}{l}\text { HVE }+ \\
\text { postgraduate study }\end{array}$ & 0.141 & 0.179 & 0.106 & 0.187 & 0.140 & 0.184 & 0.150 & 0.193 \\
\hline Tenure in current job & -0.006 & 0.018 & -0.002 & 0.018 & -0.004 & 0.018 & -0.001 & 0.018 \\
\hline $\begin{array}{l}\text { Experience before } \\
\text { current job }\end{array}$ & 0.000 & 0.012 & 0.001 & 0.012 & -0.003 & 0.013 & -0.002 & 0.013 \\
\hline \multicolumn{9}{|l|}{ Job characteristics } \\
\hline In (hourly wage) & -0.169 & 0.213 & -0.117 & 0.226 & 0.047 & 0.221 & -0.005 & 0.233 \\
\hline temporary job & 0.471 & 0.189 & 0.428 & 0.194 & $0.556^{*}$ & 0.193 & 0.478 & 0.198 \\
\hline self-employment & -0.259 & 0.281 & -0.251 & 0.282 & -0.206 & 0.283 & -0.196 & 0.285 \\
\hline autonomy & -0.089 & 0.065 & -0.089 & 0.065 & -0.072 & 0.067 & -0.079 & 0.067 \\
\hline variety & $-0.190^{*}$ & 0.065 & $-0.191^{\star}$ & 0.065 & -0.089 & 0.068 & -0.093 & 0.069 \\
\hline prestige & -0.023 & 0.066 & 0.031 & 0.067 & 0.069 & 0.068 & 0.064 & 0.069 \\
\hline room for own ideas & $-0.246^{\star}$ & 0.069 & $-0.237^{\star}$ & 0.070 & -0.133 & 0.073 & -0.138 & 0.074 \\
\hline $\begin{array}{l}\text { Education-job match } \\
\text { overeducation (years) }\end{array}$ & & & 0.016 & 0.056 & & & -0.042 & 0.060 \\
\hline on (years) & & & -0.213 & 0.140 & & & -0.137 & 0.141 \\
\hline job outside own field & & & -0.151 & 0.148 & & & -0.069 & 0.152 \\
\hline $\begin{array}{l}\text { Skill-job match } \\
\text { skill underutilisation } \\
\text { (statement } 1 \text { ) }\end{array}$ & & & & & $0.380^{*}$ & 0.059 & $0.380^{\star}$ & 0.061 \\
\hline $\begin{array}{l}\text { skill deficit } \\
\text { (statement 2) }\end{array}$ & & & & & 0.130 & 0.052 & $0.138^{*}$ & 0.053 \\
\hline Constant & 0.873 & 0.754 & 0.750 & 0.821 & -2.169 & 0.889 & -1.917 & 0.933 \\
\hline Model chi-square & 62.5 & 66.5 & & & $102.5^{\star}$ & & $103.3^{\star}$ & \\
\hline d.f. & 12 & 15 & & & 14 & & 17 & \\
\hline $\begin{array}{l}\text { change in chi-square } \\
\text { relative to model } 1\end{array}$ & - & & 4.0 & & $40.0^{*}$ & & $40.8^{*}$ & \\
\hline $\begin{array}{l}\text { change in d.f. } \\
\text { relative to model } 1\end{array}$ & - & & 3 & & 2 & & 5 & \\
\hline
\end{tabular}

* significant at $1 \%$ level.

\section{Conclusion}

In this paper we have explored the relation between educational mismatches and skill mismatches. Educational mismatches are indicated by comparing the acquired level and field of education with the level and field of education considered most appropriate for the job. Skill mismatches are indicated by worker's responses to the statements 'My current job offers me sufficient scope to use my knowledge and skills' and 'I would perform better in my current job if I possessed 
additional knowledge and skills'. In assignment theory the two concepts educational and skill mismatches are assumed to be closely related: educational mismatches imply skill mismatches which in turn have an effect on productivity and wages.

Our findings in this paper have important implications for research into the effect of education on labour market outcomes. They establish beyond reasonable doubt the importance of the distinction between schooling and skills. The results provide strong support for the assumption that the match between individual human capital and the characteristics of the job matters. In line with the predictions of assignment theory and with findings from earlier research, educational mismatches were found to have a strong effect on wages. Contrary to the assumptions of assignment theory however, educational mismatches are neither a necessary nor a sufficient condition for skill mismatches. Furthermore, only a small proportion of the wage effects of educational mismatches is accounted for by skill mismatches. Underutilisation of skills also exerts a negative effect on wages distinct from the effects of overeducation, but the effects are very small. However, skill mismatches do have a strong effect on job satisfaction and onthe-job search, after controlling for job quality, whereas educational mismatches lack any effect on these outcomes.

What do these findings mean? One explanation could be that our operationalisation of skill mismatches is inadequate. In particular the indicator for skill deficits seems to be somewhat lacking in discriminatory power, and its effects throughout are weak. Although this indicator is not entirely lacking in content and prediction validity, improving this measure is clearly an important aim for future research. Fortunately, the results pertaining to overeducation and underutilisation, which are in terms of both the theory and empirical findings by far the most important, are in no way affected by this indicator. The results on these variables hardly change at all when skill deficits and undereducation are omitted from the analyses.

There is no reason to doubt the basic validity of the indicator for skill underutilisation. There is undoubtedly some noise in this variable, as in every measure obtained through survey research, However, it seems implausible that respondents who are working below their own level to the extent that this has a strong negative effect on their wages would fail to report that their skills were not being fully utilised, if this was in fact the case. The lower wages associated with overeducation must have a different cause.

Human capital theory provides us with one possible explanation for the observed wage effects, namely that graduates with the same level of education but differing abilities are sorted in the market, with the most competent obtaining jobs 'above their own level' and the least competent obtaining jobs 'below their level'. According to this explanation, workers are rewarded according to individual productivity, which is not dependent in any major extent on the job. In other words, the apparent effects of over- and undereducation are spurious, masking unmeasured 
ability differences that are the real determinants of productivity and thence wages. This human capital explanation does not provide an explanation for our finding that a considerable proportion of workers report quite serious underutilisation of skills. This could be accounted for by a watered-down version of assignment theory, whereby the effects of educational mismatches are primarily due to differences in unmeasured abilities, but where there is still a distinct effect of skill mismatches.

Screening theory offers an alternative explanation for the observed effects. It has in common with the human capital explanation the assumption that individuals are sorted in the labour market. However, in contrast to human capital theory, screening theory asserts that individuals are sorted—and rewarded-primarily on the basis of easily observable proxies for productivity, rather than on the basis of productivity itself. One such proxy is education, but there are many others such as work experience, gender and social background. Because these other indicators are differentially distributed within educational categories, and because different employers assign different weights to each indicator, a considerable proportion of workers end up in jobs which don't match their education. Those who as a result of this sorting process end up in a job below their own level will earn less than those working at their own level, regardless of their actual level of skill, and regardless of the degree to which their skills are being utilised. In a highly institutionalised system of wage bargaining as in the Netherlands, rules about the level of the job and the educational level of the occupant are frequently incorporated into wage scales.

Our results relating to job satisfaction and in particular on-the-job search are important, since they shed light on the mechanisms through which adjustments take place in the market. Skill mismatches are an important cause of job dissatisfaction, which provide an incentive for workers to look for other work, presumably work which is better suited to their own abilities. This shows that adjustments in the labour market are strongly driven by the relation between job content and individual abilities, and less by the material and social rewards provided by work. ${ }^{9}$

\section{Acknowledgements}

This article is a revised version of a paper prepared for the conference 'Skill Measurement and Economic Analysis', 27-29 March 2000, University of Kent, Canterbury. We would like to thank Lex Borghans, Lia Potma, Timo Huijgen, and two anonymous reviewers for their comments on earlier versions of the article.

${ }^{9}$ This need not mean that such rewards are not important to workers, but could simply mean that the differences between current rewards and those available elsewhere are not sufficiently large. 


\section{References}

Allen, J. and van der Velden, R.K.W. (forthcoming). The labour market position of Dutch tertiary graduates: an international comparative analysis, Research Centre for Education and the Labour Market, Maastricht.

Cohn, E. and Khan, S.P. (1995). 'The Wage Effects of Overschooling Revisited', Labour Economics, 2, 67-76.

Duncan, G. and Hoffman, S. (1981). 'The Incidence and Wage Effects of Overeducation', Economics of Education Review, 1, 75-86.

Groot, W. and Maassen van den Brink, H. (1996). 'Overscholing en verdringing op de arbeidsmarkt', Economisch Statistische Berichten, 81, 74-7.

Hartog, J. (2000). 'Over-education and Earnings: where are we, where should we go?', Economics of Education Review, 19, 131-47.

Hartog, J. and Oosterbeek, H. (1988). 'Education, Allocation and Earnings in the Netherlands: Overschooling?', Economics of Education Review, 7, 185-94.

Hersch, J. (1991). 'Education Match and Job Match', Review of Economics and Statistics, 73, 140-4.

Sattinger, M. (1993). 'Assignment Models of the Distribution of Earnings', Journal of Economic Literature, 31, 851-80.

Sicherman, N. (1991). "“Overeducation" in the Labour Market', Journal of Labour Economics, 9, 101-22.

van Smoorenburg, M.S.M. and van der Velden, R.K.W. (2000). 'The Training of School-leavers: Complementarity or Substitution?', Economics of Education Review, 19, 207-17.

Thurow, L. (1975). Generating Inequality, Basic Books, New York, NY.

Topel, R. (1986). 'Job Mobility, Search and Earnings Growth', Research in Labor Economics, 8, 199-233.

Tsang, M. and Levin, H. (1985). 'The Economics of Overeducation', Economics of Education Review, 4, 93-104.

van der Velden, R.K.W. and van Smoorenburg, M.S.M. (1997). The Measurement of Overeducation an Undereducation: Self-Report vs. Job-Analyst Method, Research Centre for Education and the Labour Market, Maastricht.

Viscusi, W. (1979). 'Job Hazards and Worker Quit Rates: An Analysis of Adaptive Worker Behavior', International Economic Review, 20, 29-58. 


\section{Appendix}

Descriptive statistics of variables used

Table A1 Interval variables

\begin{tabular}{lrc}
\hline Variable & mean & standard deviation \\
\hline Hourly wage (guilders) & 33.0 & 10.3 \\
Tenure (years) & 3.8 & 3.6 \\
Age at start of current job (years) & 31.1 & 5.1 \\
Years of overeducation & 0.6 & 1.1 \\
Years of undereducation & 0.2 & 0.5 \\
Skill underutilisation (5-point scale) & 2.2 & 1.1 \\
Skill deficit (5-point scale) & 3.3 & 1.2 \\
Autonomy in job (5-point scale) & 3.7 & 0.9 \\
Variety in job (5-point scale) & 3.9 & 0.9 \\
Prestige of job (5-point scale) & 3.3 & 0.9 \\
Room for own ideas in job (5-point scale) & 3.9 & 0.9 \\
\hline
\end{tabular}

Table A2 Dummy variables

\begin{tabular}{lc}
\hline Variable & Percentage \\
\hline Job satisfaction & 73 \\
Looking for other work & 18 \\
Level of education: & \\
University + postgraduate study & 12 \\
University only & 36 \\
Higher vocational education + postgraduate study & 37 \\
Higher vocational education only & 16 \\
Temporary job & 9 \\
Self-employed & 6 \\
Work outside own field & 20 \\
\hline
\end{tabular}

